\title{
NOA INDUSTRIAS S.A.: Un caso de éxito en el Parque Industrial de Villa El Salvador
}

\author{
Lydia Arbaiza Fermini \\ PROFESORA INSTRUCTORA DE ESAN \\ ÁREA DE ADMINISTRACIÓN Y ORGANIZACIÓN
}

\section{Introducción: una empresa exitosa}

Noa Industrias S.A. fue fundada en enero de 1994 por los hermanos Noa como pequeña empresa dedicada a la fabricación de muebles para el hogar: sala, comedor, dormitorio y otros. Está ubicada en el Parque Industrial de Villa El Salvador y funciona bajo el régimen de sociedad anónima.

En 1995, los mismos empresarios abrieron su primera tienda de atención directa al público dentro del parque industrial creando la empresa Muebles Yolanda, que se encargaría de la comercialización de los muebles. Noa Industrias S.A. se convirtió en proveedor exclusivo de Muebles Yolanda.

En 1998, debido al incremento de locales de venta directa al público en la zona, los accionistas acordaron que cada una de estas empresas funcionaría de forma independiente. Noa Industrias S.A. fabricaría y comercializaría sus produc- tos directamente al público, mientras Muebles Yolanda estaría dedicada exclusivamente a la venta directa al publico.

En la actualidad, Noa Industrias S.A. ha implementado la «Planta turística industrial', que permite al cliente observar todo el proceso productivo y participar en el diseño de muebles de sala. Próximamente, se hará lo mismo para los muebles de comedor y dormitorio.

La producción actual es de 70 juegos de sala, 10 juegos de comedor y 15 juegos de dormitorio por año, pero la capacidad instalada permitiría fabricar 500 juegos de sala, 100 juegos de comedor y 200 juegos de dormitorio. La empresa cuenta con 43 obreros y 20 empleados y sus ventas anuales alcanzan a 900 mil soles.

En los últimos años, la empresa ha recibido las siguientes distinciones:

1999 «Premio a la excelencia» Municipalidad de Villa El Salvador y Banco de Crédito 
1999 «Premio Pyme»

Prompyme

1999 «Empresa de la década» Prómpex

2000 «Mejor empresa de Villa El Salvador»

Municipalidad de Villa El Salvador y Ministerio de Industria, Turismo, Integración y Negociaciones Comerciales Internacionales (Mitinci)

2000 «Creatividad empresarial: equipo y decoración»

Universidad Peruana de Ciencias Aplicadas, UPC

2000 «Empresa del año» Asociación Empresa Peruana del Año y Universidad San Martín de Porres

El señor Basilio Noa enuncia así la misión y visión de su empresa:

\section{Misión}

«Somos una empresa dedicada a la fabricación y comercialización de muebles para el hogar y buscamos ser competitivos en los atributos que los clientes valoran: calidad, tiempo de entrega y costos.

Consideramos al cliente como el $» j e f e$ máximo» de la empresa.

Innovamos continuamente modelos y diseños con la finalidad de asegurar la satisfacción y fidelidad de nuestros clientes.

Contamos con un equipo humano altamente calificado, leal, honesto e identificado con la empresa y con nuestros clientes; para ellos buscamos la realización personal».
Visión

«Aspiramos a ser reconocidos por nuestros clientes y nuestro entorno como la mejor empresa en la fabricación y comercialización de muebles de alta calidad para el hogar en nuestro medio en el mediano plazo.

Buscamos expandirnos en el mercado nacional e internacional.

Aspiramos a alcanzar la excelencia a través de una adecuada gestión de todos los recursos de la empresa».

¿Cómo ha logrado Noa Industrias S.A. operar en un entorno tan competitivo, mantenerse en el mercado y ser una empresa sostenible a lo largo del tiempo?

\section{El sector de fabricación de muebles para el hogar en 1994}

Según datos del Mitinci, en 1994 había, aproximadamente, 18437 pequeñas empresas dedicadas a la fabricación de muebles de madera en todo el ámbito nacional, las que representaban el $21,3 \%$ de la totalidad de pequeñas y microempresas. En Lima Metropolitana había 7770 empresas y de éstas 568 estaban ubicadas en Villa El Salvador. En el parque industrial de este distrito había aproximadamente 180 empresas, es decir, el $1 \%$ del total nacional. Cabe señalar que las cifras del Mitinci no incluían empresas informales.

Muchas pequeñas empresas quebraron como consecuencia del shock económico de 1991; el sector recién empezó a reactivarse a partir de 1993, a raíz del periodo de pacificación que siguió a la captura del líder senderista Abimael Guzmán. Los años de la subversión fueron muy difíciles, tanto por la voladura de 
torres de alta tensión como por el crecimiento de los grupos violentistas en Villa El Salvador.

En esa época, el liderazgo de la industria del mueble recaía en Hogar S.A. y en Muebles Dany, mientras empresas como Casagrande y Sanicerámica empezaban a posicionarse en el mercado.

Las empresas del Parque Industrial de Villa El Salvador vendían a intermediarios; muy pocas lo hacían al consumidor final porque no contaban con tiendas para la exhibición de sus productos. Su grado de desarrollo tecnológico era muy pobre, ya que la mayoría trabajaba con máquinas artesanales. La producción estaba dirigida a diferentes estratos sociales, no había mucha variedad de diseños ni de modelos de muebles, el volumen de producción era limitado y no había desarrollo de marca, aunque algunos productos eran de muy buena calidad. El costo de la mano de obra era bajo, por lo general la retribución era al destajo. No se advertía una amenaza muy notoria de productos importados, los precios de los muebles eran muy bajos, la venta a los intermediarios era por lo general al crédito y/o a consignación, con márgenes de utilidad que en algunos casos apenas cubrían los costos.

\section{Antecedentes de Noa Industrias}

En 1985, uno de los hermanos Noa, Basilio, visitó el distrito de Villa El Salvador con un compañero de estudios. Éste le informó que había terrenos industriales disponibles para pequeños empresarios y que si estaba interesado en adquirir uno podía inscribirse en la Asociación de Pequeños Artesanos e Industriales de Villa El Salvador, APIAVES. En los contratos de compra y venta, una cláusula recalca- ba expresamente que estos terrenos debían destinarse solamente a plantas de producción (ver anexo).

Entre los años 1986 y 1987 hubo una gran demanda de muebles de fabricación nacional dirigida a los pequeños empresarios del cono sur. Provenía principalmente de las diferentes tiendas de muebles situadas en la avenida Arenales y en la gran Lima, y también de los grandes almacenes que operaban en la ciudad. Y casi todos los fabricantes de muebles de madera del cono sur vendían su producción a estos establecimientos. Durante los dos años siguientes, 1988 y 1989, la crisis económica por la que atravesaba el Perú se agudizó debido a la desacertada gestión del gobierno aprista. Las ventas de muebles para el hogar empezaron a caer y llegaron a su punto más bajo en 1990, luego del shock económico aplicado por el entrante gobierno de Fujimori con el objetivo de iniciar un programa de ajuste y estabilización. Para entonces, las pequeñas y microempresas, sobre todo las del sector de muebles de madera, podían considerarse en ruinas.

Una de estas microempresas era la de Basilio Noa, establecido en el parque industrial desde mediados de la década de los ochenta y abastecedor de algunas tiendas de la gran Lima, como las demás microempresas del parque industrial. Las ventas se hacían a crédito o a consignación, las utilidades eran mínimas y muchas veces se perdía el capital porque los clientes, básicamente comerciantes intermediarios, simplemente no pagaban. La escasez de demanda redujo el parque industrial a un centro de actividades que vendía apenas para el sustento diario. Los fabricantes se vieron obligados a agruparse para formar una «olla común» 
En 1993, a solicitud de su gremio, Basilio Noa aceptó el reto de gerenciar la Autoridad Autónoma del Proyecto Especial del Parque Industrial del Cono Sur de Villa el Salvador. Los gerentes y autoridades anteriores se habían mostrado incapaces para solucionar los problemas más importantes que afrontaban los microempresarios, como los relacionados con la adjudicación de los lotes y el proceso de titulación, a lo que se añadía el caos político que vivía Villa el Salvador por el mal manejo de sus autoridades ediles y el fenómeno terrorista que asolaba el país. Y todo esto sumado a la crisis económica nacional.

Debido a sus nuevas responsabilidades, Basilio Noa se vio ante la necesidad de encargar la administración de su microempresa a una persona de toda su confianza. Pensó entonces en sus hermanos y en la posibilidad de sumarlos a su negocio. Además, pensó que si todos participaban y aportaban capital, la empresa podía crecer más rápido. De esta manera, a principios de 1994 surgió Noa Industrias S.A., la que empezó trabajando en el mismo entorno de ventas bajas, crédito de hasta 120 días a los clientes, mínimas utilidades, recesión y terrorismo.

\section{El primer año de operación}

Cuando la empresa inició sus actividades, el trabajo se pagaba a destajo, se utilizaba sólo herramientas básicas y el personal se adecuaba rápidamente al tipo de muebles que solicitaban los clientes. Podía decirse que el proceso de producción era flexible. Se fabricaban comedores, dormitorios para adultos y niños, y carpetas para niños. No se realizaba control de calidad al producto acabado ni al proceso productivo, salvo en algunas ocasiones. No se guardaba madera ni otros insumos en almacén; los materiales se compraban cuando se recibía algún pedido. En los cuadros que se presenta a continuación se muestra algunos datos del primer año de operación de Noa Industrias S.A.

\section{Maquinaria}

\begin{tabular}{|l|c|c|c|}
\hline Tipo & Antigüedad & Procedencia & Cantidad \\
\hline Sierra circular & 3 & Nacional & 2 \\
\hline Tupi & 15 & Nacional & 1 \\
\hline Sierra cinta & 5 & Nacional & 1 \\
\hline Garlopa & 2 & Taiwán & 1 \\
\hline Torno & 15 & Nacional & 1 \\
\hline
\end{tabular}

Fuente: Noa Industrias S.A., 1994. 


\section{Recursos humanos del área de producción}

\begin{tabular}{|l|c|c|}
\hline \multicolumn{1}{|c|}{ Cargo } & Número & Antigüedad (años) \\
\hline Jefe de planta & 1 & 5 \\
Carpinteros maestros & 2 & 4 \\
Ayudantes de carpintería & 2 & 1 \\
Pintores maestros & 2 & 4 \\
Ayudantes de pintores & 2 & 2 \\
\hline Total & 9 & \\
\hline
\end{tabular}

Fuente: Noa Industrias S.A., 1994.

\section{Recursos humanos del área administrativa}

\begin{tabular}{|l|c|c|}
\hline Cargo & Nivel educativo & Antigüedad (años) \\
\hline Gerente & Superior & 1, fundador \\
Asistente administrativo & Superior & 1, fundador \\
\hline Total & & 2 \\
\hline
\end{tabular}

Fuente: Noa Industrias S.A., 1994.

\section{Estadísticas generales}

\begin{tabular}{|l|l|}
\hline Rubro & \\
\hline Capacidad instalada & $\begin{array}{l}10 \text { juegos de comedor } \\
20 \text { juegos de dormitorio } \\
50 \text { carpetas }\end{array}$ \\
\hline Pemanal & $\begin{array}{l}60 \text { juegos de comedor } \\
120 \text { juegos de dormitorio } \\
100 \text { carpetas }\end{array}$ \\
\hline Número de trabajadores & 11 personas \\
\hline Ventas anuales & 130 000 nuevos soles \\
\hline Tipo de propiedad & Propia \\
\hline Líneas principales & Comedor, 37\% \\
& $\begin{array}{l}\text { Dormitorio, } 57 \% \\
\text { Carpetas, } 6 \%\end{array}$ \\
\hline
\end{tabular}

Fuente: Noa Industrias S.A., 1994. 


\section{Principales proveedores}

\begin{tabular}{|l|l|l|l|l|}
\hline $\begin{array}{l}\text { Materias primas } \\
\text { e insumos }\end{array}$ & Proveedores & Procedencia & Cantidad & \multicolumn{1}{|c|}{ Relación } \\
\hline Maderas & $\begin{array}{l}\text { Maderera Lam } \\
\text { Maderera Batto } \\
\text { Bosque Maderas S.A. } \\
\text { Maderera Lozano } \\
\text { Maderera Videla }\end{array}$ & Nacional & Más de 10 & $\begin{array}{l}\text { Se consideran por } \\
\text { tener madera en } \\
\text { stock y ofrecer } \\
\text { precios razonables. }\end{array}$ \\
$\begin{array}{l}\text { Tripley } \\
\text { Anchapado } \\
\text { Aglomerados }\end{array}$ & $\begin{array}{l}\text { Representaciones } \\
\text { Martín Pfuyo }\end{array}$ & Nacional & Más de 10 & $\begin{array}{l}\text { Mantienen los } \\
\text { precios más bajos del } \\
\text { mercado y ofrecen } \\
\text { productos de buena } \\
\text { calidad. }\end{array}$ \\
\hline $\begin{array}{l}\text { Pintura } \\
\text { Thiner } \\
\text { Selladora }\end{array}$ & $\begin{array}{l}\text { Ferretería Pfuyo } \\
\text { Ferretería San Antonio }\end{array}$ & Nacional & Más de 5 & $\begin{array}{l}\text { Sirven para acabados } \\
\text { y son de buena marca } \\
\text { de precios bajos. }\end{array}$ \\
\hline $\begin{array}{l}\text { Clavo } \\
\text { Lija } \\
\text { Cola }\end{array}$ & $\begin{array}{l}\text { Ferretería Pfuyo } \\
\text { Ferretería San Antonio }\end{array}$ & Nacional & Más de 5 & $\begin{array}{l}\text { Precios razonables, } \\
\text { stock permanente y } \\
\text { de buena calidad. }\end{array}$ \\
\hline
\end{tabular}

Fuente: Noa Industrias S.A., 1994.

\section{Principales competidores}

\begin{tabular}{|l|l|}
\hline Anabel S.A. & $\begin{array}{l}\text { Incursiona en la fabricación de muebles para el hogar. } \\
\text { No vende directamente al publico, sino a intermedia- } \\
\text { rios. No hace publicidad. Su tecnología es similar a la } \\
\text { de Noa Industrias S.A. }\end{array}$ \\
\hline Serapio Bravo & $\begin{array}{l}\text { Fabricante de dormitorios. Trabaja como persona } \\
\text { natural. No hace publicidad ni tiene marca. Vende a } \\
\text { intermediarios. Ofrece buena calidad y modelos y } \\
\text { diseños muy aceptables. }\end{array}$ \\
\hline Murivilca & $\begin{array}{l}\text { Empresa familiar que trabaja como persona natural. } \\
\text { No tiene tienda y vende a intermediarios. Su principal } \\
\text { línea de producción son los muebles de oficina, } \\
\text { fabrica dormitorios en menor cantidad. }\end{array}$ \\
\hline Justo Borja & $\begin{array}{l}\text { Empresa familiar, produce muebles para el hogar, } \\
\text { especialmente comedores y dormitorios. Vende a } \\
\text { intermediarios, no tiene tienda ni hace publicidad. } \\
\text { Ofrece buena calidad. }\end{array}$ \\
\hline
\end{tabular}


(continúa Principales competidores)

\begin{tabular}{|c|l|}
\hline MEBLYR S.R.L. & $\begin{array}{l}\text { Especialidad en muebles para el hogar: dormitorios y } \\
\text { comedores. Buena calidad. Vende a intermediarios. }\end{array}$ \\
\hline Marfisa S. A. & $\begin{array}{l}\text { Uno de los mejores fabricantes de dormitorios y } \\
\text { comedores. Buena calidad. No tiene tienda ni hace } \\
\text { publicidad, vende a grandes almacenes (Saga, Hogar). } \\
\text { Precios altos. }\end{array}$ \\
\hline Famacsa S.A. & $\begin{array}{l}\text { Fabrica dormitorios y comedores. Ofrece buena } \\
\text { calidad, precios bajos y variedad de diseños y } \\
\text { modelos. Abastece a grandes almacenes. No hace } \\
\text { publicidad. }\end{array}$ \\
\hline
\end{tabular}

Fuente: Noa Industrias S. A., 1994

\section{Estrategias}

Finalizado 1994 y luego de deliberar y analizar la situación del entorno y los problemas que aquejaban a la empresa, los hermanos Noa decidieron iniciar acciones estratégicas.

Entre las acciones específicas que ejecutó la empresa puede mencionarse la subcontratación de mano de obra en los procesos que no eran fijos, la negociación con el proveedor de madera para lograr la integración hacia atrás y el convencimiento a los accionistas de la necesidad de aumentar el capital de trabajo para lograr solvencia y un volumen suficiente de producción.

El señor Basilio Noa había estudiado diversos cursos de especialización para ejecutivos en ESAN y era un convencido de la necesidad de la capacitación y del manejo profesional de las empresas.

Con base en el análisis estratégico y a lo largo de los años, Noa Industrias S.A. realizó una serie de cambios en su estilo de trabajo, no sólo en lo referente a la producción, también en cuanto al manejo y administración del personal.

En primer lugar, tomó en consideración a los trabajadores. Hizo lo posible por mejorar el ambiente laboral, estableciendo sueldos y salarios de acuerdo con el mercado, observando puntualidad en el pago y otorgando los beneficios establecidos por ley. Con la misma orientación, la empresa dio relevancia a la continuidad laboral, así como a la oportunidad de capacitación y desarrollo profesional de sus trabajadores.

En segundo lugar, tuvo en cuenta las aspiraciones de rentabilidad y oportunidad de inversión de los accionistas, con lo que logró la confianza y el respaldo de éstos para la ejecución de los cambios necesarios.

Pensando en los clientes, la empresa hizo esfuerzos para mejorar la calidad de sus productos -fabricando variedad de diseños y modelos- y brindar una atención esmerada al público. Además estableció precios moderados, facilidades de pago y garantías y se acostumbró a cumplir es- 
trictamente los plazos de entrega. Factor esencial al respecto fue la implementación de la planta turística industrial, que acerca al cliente al proceso mismo de fabricación del mueble y le permite ver el avance de su pedido.

Con respecto a los proveedores, Noa Industrias S. A. incentivó la fidelidad con puntualidad en los pagos y un calendario de abastecimiento; y con relación a su gremio, siguió participando en forma activa y continua en las asociaciones comerciales y apoyándolas económicamente.

\section{Noa Industrias S.A. en la actualidad}

Cada año representa un nuevo reto para la supervivencia y crecimiento de Noa Industrias, que se está preparando con el fin de enfrentar las nuevas circunstancias. Pensando en la mejora de la empresa, Basilio Noa ha planeado llevar a cabo algunas acciones específicas. Entre ellas, la búsqueda de canales de distribución en
Lima y provincias, con la finalidad de ampliar el mercado; la implementación de tecnologías de información, principalmente software para manejo de inventarios y acceso a Internet; la capacitación especializada dirigida al personal de nivel gerencial; la contratación de personal calificado para el área de marketing y el incremento de la publicidad y la promoción de los productos, así como encuestas a clientes orientadas a definir una marca que impulse las ventas. Con todo ello, y aprovechando el aumento de las exportaciones de muebles para el hogar, Basilio Noa quiere desarrollar un producto competitivo con estándares de calidad que pueda ofertarse al mercado latinoamericano.

En las siguientes figuras se puede apreciar el organigrama, el diagrama de flujo y la distribución de planta actuales de la empresa. También un cuadro que resume las fases del proceso de producción.

\section{Organigrama de Noa Industrias S. A}

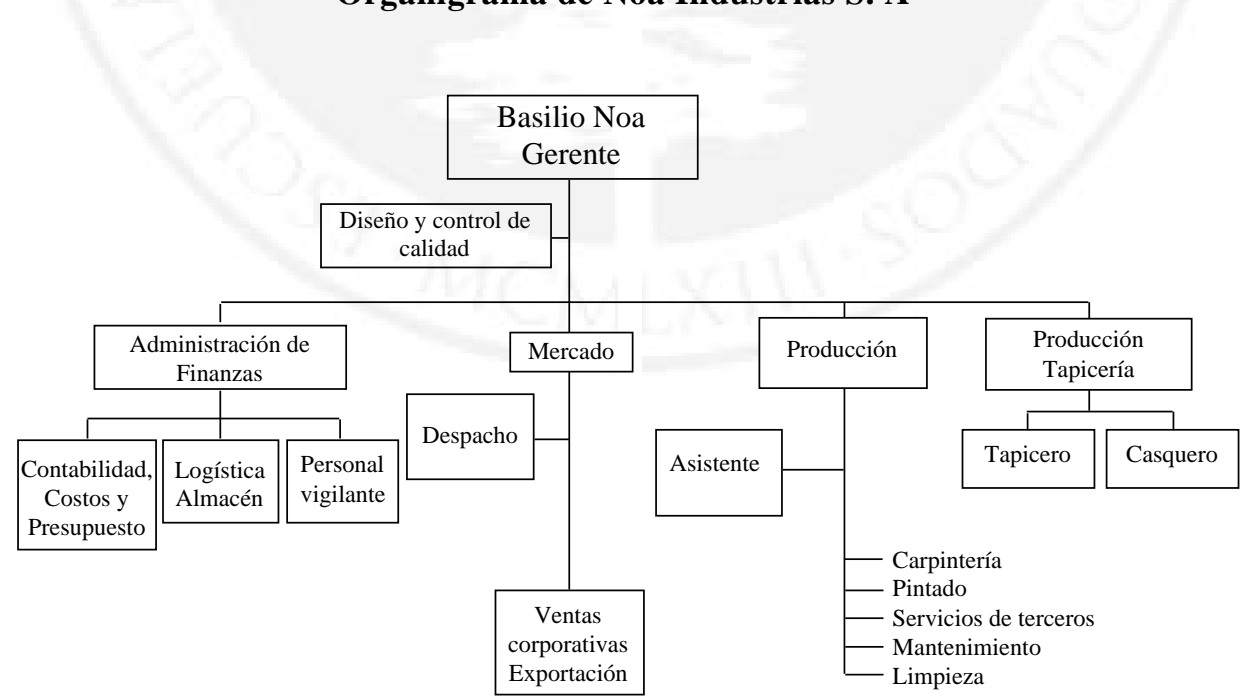




\section{Diagrama de flujo de Noa Industrias S.A.}

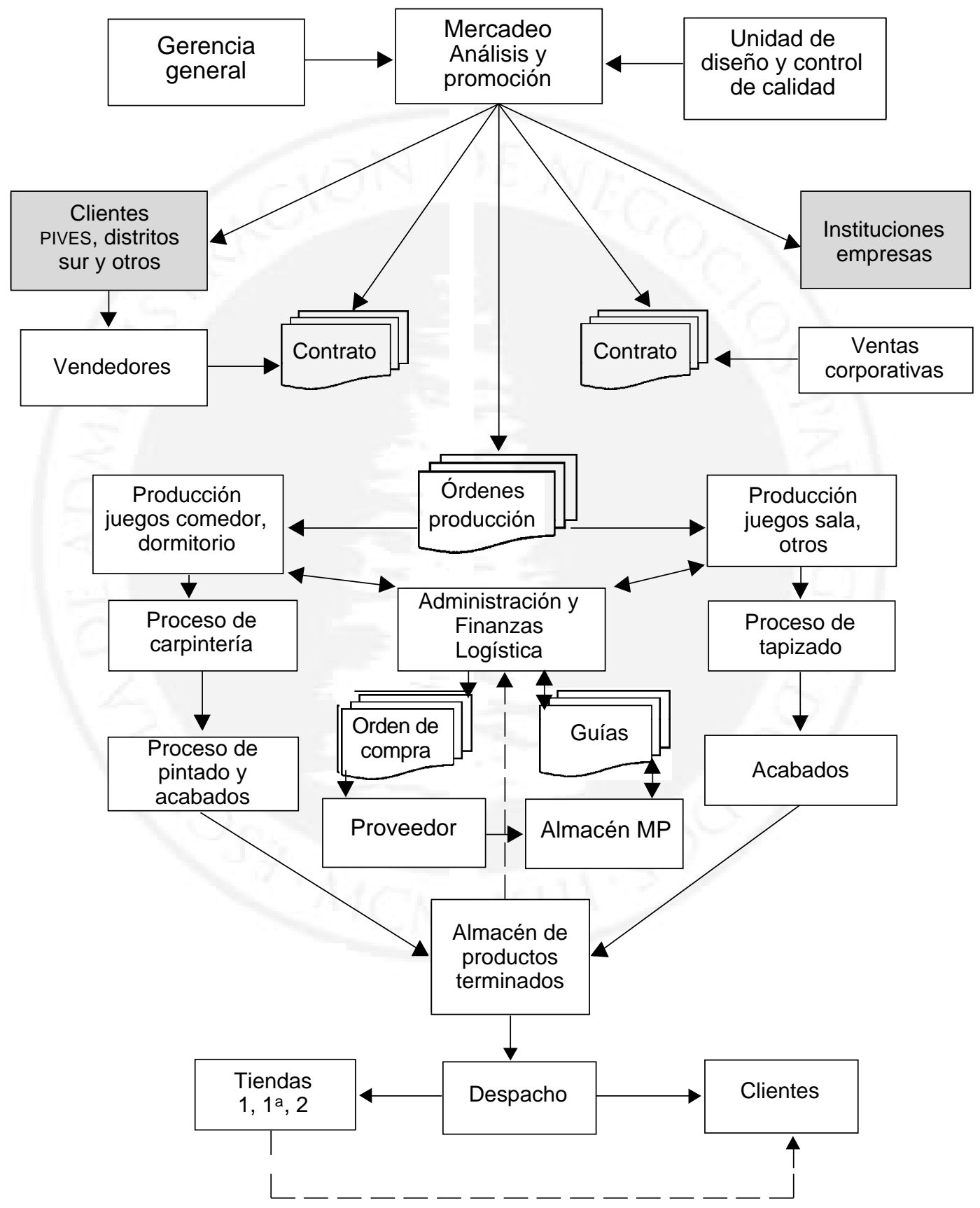


Distribución de planta de producción: comedores y dormitorios Noa Industrias S.A.

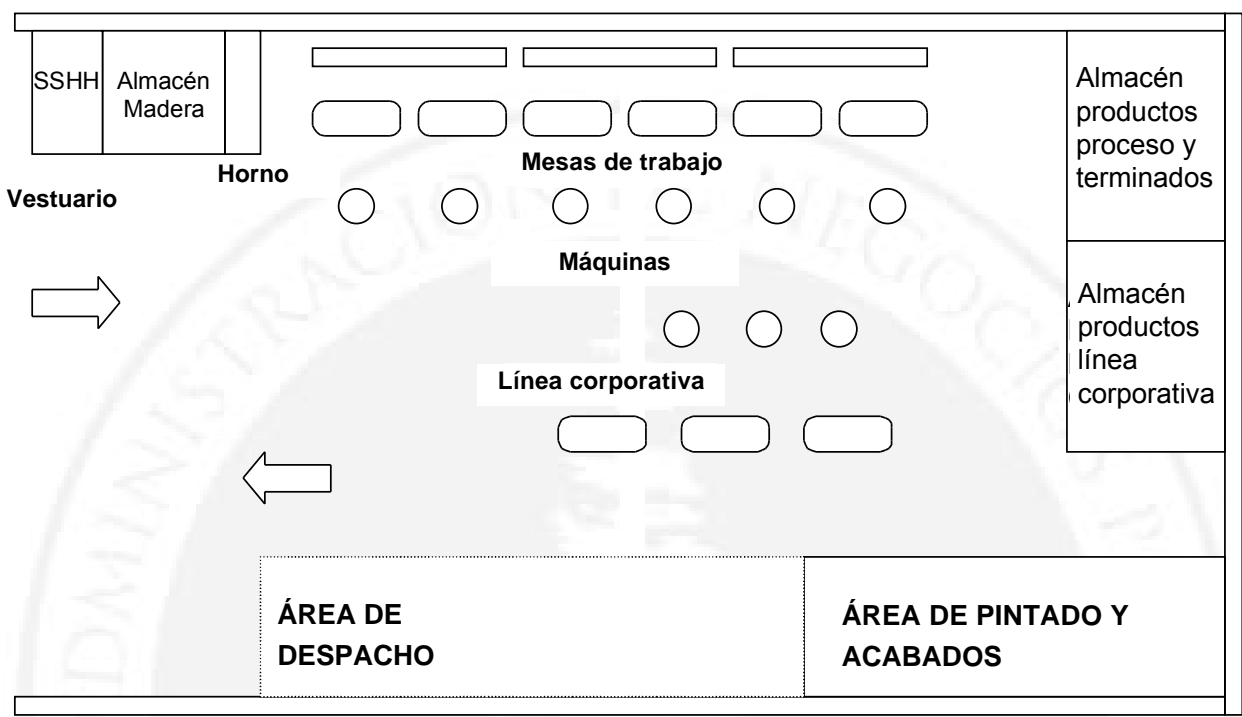

Fases del proceso de producción

\begin{tabular}{|cl|cl|}
\hline Fase & Nombre & Fase & Nombre \\
\hline 1 & Habilitación & 6 & Encolado \\
\hline 2 & Selección & 7 & Prensado \\
\hline 3 & Secado & 8 & Pintado \\
\hline 4 & Cepillado & 9 & Tapizado \\
\hline 5 & Cortado & & \\
\hline
\end{tabular}

Fuente: NOA Industrias S.A., 2001. 


\section{La producción y el mercado}

Los productos más importantes de la empresa, de acuerdo con su participación directa en las ventas, son los juegos de sala y de dormitorio, como se puede observar en el siguiente cuadro.

\begin{tabular}{|l|c|}
\hline \multicolumn{1}{|c|}{ Tipo de producto } & Contribución a las ventas (en \%) \\
\hline Confortables (juegos de sala) & 57 \\
\hline Juegos de dormitorio & 21 \\
\hline Juegos de comedor & 15 \\
\hline Otros & 7 \\
\hline Total & 100 \\
\hline
\end{tabular}

Fuente: Noa Industrias S.A., 2001.

La distribución de las ventas de la empresa, según zonas geográficas, es la siguiente:

\section{Contribución a las ventas por zonas geográficas}

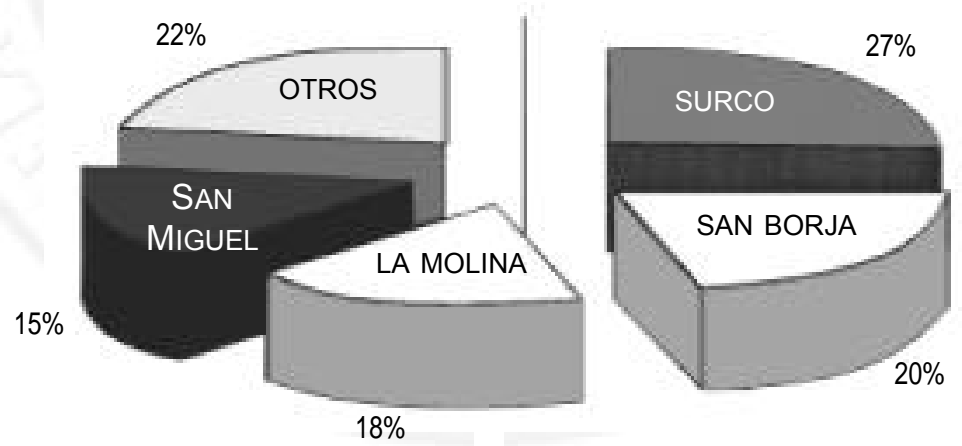




\section{Determinación de precios}

Según el indicador de determinación de precios, que permite establecer la capacidad de la empresa para determinar el precio de sus productos a través de los diferentes factores que lo condicionan, Noa Industrias ejerce un control parcial sobre estos factores, ya que el valor del mencionado indicador es de 78\%; es decir, la empresa no puede controlar la influencia de algunos factores externos.

\section{Estructura de costos}

Un ejemplo ayudará a establecer la estructura de costos de la empresa, que considera los materiales, la mano de obra y otros. Los costos involucrados en la fabricación de un juego de dormitorio son los que se especifican a continuación.

El juego de dormitorio «Princesa» consta de:

\section{1 cómoda}

1 cama de dos plazas

2 veladores

1 espejo

\section{Materiales (a)}

\begin{tabular}{|l|l|c|c|}
\hline Materiales & Cantidad & Precio unitario* & Total* $^{*}$ \\
\hline Madera & $80 \mathrm{p}^{2}$ & 1,2 & 116,0 \\
\hline Madera & $01 \mathrm{Pl}$ & 18,0 & 18,0 \\
\hline Cola & $1 / 10 \mathrm{gl}$ & 10,0 & 1,0 \\
\hline Clavo & $1 / 10 \mathrm{~kg}$ & 3,0 & 0,3 \\
\hline Lija ${ }^{\circ}{ }^{\circ} 60$ & $02 \mathrm{unidades}$ & 1,0 & 2,0 \\
\hline Base duco & $01 \mathrm{gl}$ & 18,0 & 18,0 \\
\hline Laca blanca & $1 / 2 \mathrm{gl}$ & 20,0 & 10,0 \\
\hline Laca brillante & $1 /{ }_{4} \mathrm{gl}$ & 20,0 & 5,0 \\
\hline Thiner acrílico $03 \mathrm{gl}$ & 6 & 18,0 & 2,4 \\
\hline Lija.$^{\circ} 120$ & $03 \mathrm{unidades}$ & 0,8 & 0,8 \\
\hline Talco americano & $01 \mathrm{~kg}$ & 0,8 & 191,5 \\
\hline Total & & & \\
\hline
\end{tabular}

* En unidades monetarias. 


\section{Mano de obra (b)}

\begin{tabular}{|l|c|}
\hline $\begin{array}{l}\text { Mano de obra por } \\
\text { juego de dormitorio }\end{array}$ & Costo* $^{*}$ \\
\hline Selección de madera & 5 \\
\hline Cepillado & 10 \\
\hline Corte & 20 \\
\hline Espigado & 15 \\
\hline Huequeado & 15 \\
\hline Lijado & 10 \\
\hline Armado & 30 \\
\hline Acabado & \\
\hline Habilitado en base duco & 100 \\
\hline Acabado en brillante & 50 \\
\hline Total & 255 \\
\hline
\end{tabular}

* En unidades monetarias.

\section{Otros (c)}

\begin{tabular}{|l|c|}
\hline \multicolumn{1}{|c|}{ Otros } & Costo* $^{*}$ \\
\hline Pulidor & 0,8 \\
\hline Cera líquida & 0,2 \\
\hline Lápiz & 0,1 \\
\hline Waype & 1,0 \\
\hline Algodón & 1,0 \\
\hline Espejo & 8,0 \\
\hline Total & 11,1 \\
\hline
\end{tabular}

* En unidades monetarias.

$$
\begin{aligned}
& \text { Total }(\mathbf{a}+\mathbf{b}+\mathbf{c}) \quad=\quad 191,5 \\
& 255,0 \\
& 11,1 \\
& 457,6 \text { unidades monetarias }
\end{aligned}
$$




\section{Mano de obra}

Actualmente, el personal de planta está integrado por 43 operarios, mientras que el personal administrativo comprende 20 personas.

\begin{tabular}{|l|c|c|}
\hline Área & Personal masculino & Personal femenino \\
\hline Producción & 40 & 3 \\
\hline Ventas & 2 & 6 \\
\hline Empleados administrativos & 2 & 3 \\
\hline Mandos medios & 2 & 0 \\
\hline Dirección & 4 & 13 \\
\hline Total & 50 & \\
\hline
\end{tabular}

Fuente: Noa Industrias, 2001.

\section{GUÍA PARA EL INSTRUCTOR}

\section{Resumen ejecutivo}

El caso presenta un ejemplo exitoso en la industria del mueble, en particular en el Parque Industrial de Villa El Salvador. Más allá de los logros de la empresa Noa Industrias S.A. en el entorno que le tocó enfrentar, también es un mensaje sobre el desempeño alentador del mencionado parque, en comparación con otros parques industriales que ni siquiera sobrevivieron como concepto.

El de Basilio Noa no es el caso típico del microempresario que administra empíricamente una empresa familiar. En términos de la estrategia aplicada para sobrevivir y del manejo del personal se advierte una diferencia con el estándar observado en las microempresas.

\section{Objetivos académicos}

Los objetivos que se pretende alcanzar con este caso son los siguientes:
- Revisar la estrategia aplicada por la empresa en un sector como el de muebles, de intensa competencia.

- Reconocer las prácticas aplicadas para lograr una empresa sostenible en el tiempo.

- Encontrar las acciones tomadas de acuerdo con las situaciones de cambio que se iban presentando.

- Permitir a los estudiantes aplicar sus conocimientos sobre administración, estrategia o recursos humanos a una organización y sector específicos.

\section{Preguntas para guiar la discusión}

- ¿Cuáles son los grupos de interés interno?

- ¿Cuáles son los grupos de interés externo?

- ¿Cuáles son las influencias de las fuerzas del entorno sobre estos grupos? 
- ¿Cuáles son las principales fortalezas y debilidades de Noa Industrias?

- ¿Cuáles son las principales oportunidades y riesgos?

- ¿Cuál es al matriz del perfil competitivo?
- ¿Cuál es el resultado del análisis de las cinco fuerzas de Porter?

- ¿Qué opciones estratégicas tiene la empresa? 


\section{ANEXO \\ El Parque Industrial de Villa El Salvador}

\section{Reseña histórica del distrito de Villa El Salvador}

En 1971, un grupo de invasores de Pamplona, distrito de San Juan de Miraflores, fue reubicado en los terrenos de lo que hoy es el distrito de Villa el Salvador, arenal en verano y floreciente loma en los inviernos húmedos.

En su lucha por acceder a un terreno propio, los pobladores de este distrito, en su mayoría provincianos provenientes de la sierra, demostraron capacidad de organización y de movilización y disposición para asumir riesgos y enfrentar nuevos retos. Su primera organización fue la Comunidad Urbana Autogestionaría de Villa El Salvador, CUAVES.

A lo largo de los años han recibido apoyo de la iglesia Católica, de diferentes organismos del Estado y de algunas organizaciones no gubernamentales, tanto en recursos humanos y materiales como en diferentes aspectos técnicos y organizativos.

En 1973, en la asamblea de pobladores el lema central fue: «Antes que casa, fábricas». Y en 1974, el gobierno de Juan Velasco Alvarado reservó un área de 382 hectáreas para el futuro parque industrial, tal como hiciera en muchas otras ciudades. Pobladores y dirigentes compartían el sueño de la industrialización a partir de grandes inversiones, preferentemente estatales y autogestionarias, y para las cuales se requeriría terrenos de gran tamaño y suministro de energía eléctrica de alta tensión.

Hasta 1987, el Parque Industrial de Villa El Salvador fue administrado por diferentes entidades estatales, tales como el Ministerio de Vivienda, el Ministerio de Industria, Comercio, Turismo e Integración y el Instituto Nacional de Planificación.
Las organizaciones de pequeñas y microempresas generadas espontáneamente en Villa El Salvador se multiplicaron a partir de 1983. Surgieron APISUR, APIAVES, ADEICOSUR, Los Kipus y José Carlos Mariátegui, las que posteriormente se reunieron para formar la Asociación de Pequeñas y Medianas Empresas de Villa el Salvador, APEMIVES, con la finalidad de dar una nueva orientación al parque industrial y canalizar el apoyo del Estado y de algunos organismos no gubernamentales. En 1986, el apoyo de la Organización de las Naciones Unidas para el Desarrollo Industrial, Onudi, hizo posible la creación del proyecto Parque Industrial Cono Sur, oficializado mediante decreto supremo 133-87-EF del 4 de junio de 1987.

El 28 de julio de 1988 se promulgó la ley 24877, que creaba la Autoridad Autónoma del Proyecto Especial del Parque Industrial de Villa El Salvador, entidad administradora cuya conducción quedó a cargo de un directorio presidido por el alcalde del distrito.

Con estrecha colaboración de entidades nacionales de asesoría y del municipio, y gracias al papel fundamental de APEMIVES, el rediseño del parque industrial otorgó prioridad a los lotes para pequeñas empresas.

\section{Comentarios en torno al parque industrial}

Las siguientes citas han sido extraídas de las entrevistas realizadas, entre diciembre de 1991 y febrero de 1992, tanto a empresarios como a funcionarios de organismos privados y estatales, e incluidas en el documento que la Onudi preparó sobre el Parque Industrial de Villa El Salvador.

Sobre el diseño original del parque industrial

«Cuando el lema fue 'Antes que casas, fábricas' estoy hablando de 1973, yo me reía, no 
en el sentido de ironizar demasiado, sino sabiendo que la gente viene a un pueblo joven por su casa, por su lote. Pero ése fue el lema, de CUAVES, bien grande. Cuando se crea el distrito se va haciendo realidad, pero es un proceso, no se podía sacar del cielo las fábricas».

«El PI se concibió como un espacio del proyecto original para desarrollar empresas de propiedad social. Hoy ha sido desnaturalizado».

«El modelo de desarrollo industrial basado en la inversión del Estado para desarrollar, en diferentes zonas del país, infraestructuras de servicios para crear urbanizaciones industriales, no resultó. Es que no se trata simplemente de construir una urbanización, para que con una suerte de varita mágica le dé un toque magistral y la convierta en poco tiempo en un polo de desarrollo. La urbanización y los servicios son un mecanismo, pero hay que complementar la materia primera con la potencia productiva de una zona y con los diferentes mercados».

\section{Sobre el rediseño del parque industrial}

«De la unión del sector empresarial sale una especie de presión que se comienza a aquilatar y a respetar por parte de la autoridad local. Cuando están unidos, la gente ya va de manera concreta; la unión hace que los políticos presten atención y recién lo miren convertido en un proyecto que no existía antes».

«Para que se pueda dar una experiencia como la de VES, se necesita mucha organización de toda la gente involucrada. En este sentido, la gente de Villa tiene esto, ha logrado una identidad, lo cual es difícil de encontrar en otro lugar».

«Tenemos la experiencia comunal de CUAVES, que ha fracasado [...]. Cambia el ejecutivo y cambian todos, entonces es un permanente fracaso hasta el día de hoy...».
«El nombre de Onudi te jala mucha cooperación. Te abre muchas puertas, tú ni te imaginas. Son buenos relacionistas públicos».

«El papel de Onudi al principio fue muy importante, porque gracias al buen nombre de Onudi el Gobierno reconoció la importancia del parque y abrió una partida presupuestal para su reactivación».

\section{Sobre los elementos centrales del nuevo diseño}

«La idea es que la AA pudiera ser una empresa pública mixta, en donde haya participación de los empresarios».

«Se vio la necesidad de ir llamando al apoyo, al auxilio de diversas instituciones, porque veíamos que nuestra capacidad de resolver los problemas era limitada completamente. Ten en cuenta que aquí se tiene que hacer construcciones, diseñar una serie de propuestas alternativas, se tiene que dar apoyo y asesoría técnica productiva, racionalización de la producción, todo lo que es capacitación, comercialización. En fin, es un universo tan vasto de cosas que es prácticamente imposible que un grupo tan pequeño pudiera resolver».

«Con los empresarios, la cooperación técnica y nosotros establecemos un triángulo para llevar a cabo los proyectos».

«También podemos hablar de lo original de la idea de los maquicentros, como centros de servicio que permiten articular a las industrias sobre la base de servicios comunes a los cuales no tendrían acceso individualmente».

\section{Sobre el proceso}

«El empresario de VES ha captado en el camino que el poder de la organización le puede dar acceso a servicios gratuitos. Se ha dado cuenta de que agrupadamente se puede llegar al servicio subsidiado. Eso tiene que comenzar necesariamente a corregirse y a cambiar». 
«Nos han dado apoyo para ir a eventos tipo Subcontrata, Feria del Hogar [...]. Nos ayudan a vender los stocks que tenemos [...]. Nos subsidian un poco el stand, a decorar, un poco de trípticos $[\ldots]$. en ese aspecto [...] es una pequeña ayuda. Esto nos puede permitir tener contactos con persona que estén interesadas en comprar volúmenes, sobre todo. Nuestra participación anterior en la Feria Hogar ha tenido resultados positivos, allí se vende regular cantidad...».

«Yo me he sentido satisfecho del apoyo a la participación en ferias (Feria del Pacífico año 1989) [...] exhibimos nuestra prensa y unos aros artilleros y tuvimos buena acogida [...] vendimos sobre todo a provincias [...] salió a cuenta».

«El crédito es muy caro. Además no hay mucha ayuda directa. Muchas donaciones hay que pagarlas».

«Estamos atravesando por una situación muy difícil debido a la falta de ventas. Antes vendía casi al contado y me buscaban, ahora tengo que dar crédito y cada vez a más largo plazo, sino no puedo vender. Pero eso me paraliza, porque mi capital ya no alcanza. Regresa cada vez más lentamente, no se puede aguantar más. Frente a esta situación nuestra decisión ha sido dedicarnos a la venta de servicios, eso sí nos deja ganancias en lugar que nosotros financiemos a otros con nuestro capital de trabajo. Igualmente no podemos construir nuestro local, porque nuestros problemas de financiamiento se han vuelto muy pesados».

\section{Sobre la situación al año 1992}

«Uno de los principales errores de la AA ha sido no definir con claridad su relación con los gremios en términos de una relación de servicios, de promoción y de negocios (compra y venta de bienes y servicios). A mí me parece que la AA muchas veces ha equivocado su papel, sustituyendo la labor empresarial de los pequeños industriales. Entonces estos industriales han pensado que ésta era la labor de la AA. Encargada de venderles el producto, de darle la plata donada, darles los lotes baratos».

«Al inicio se dio una actitud muy paternalista de parte de la AA, luego demasiado drástica. Parece que cuando no había nada, no había muchos recursos, se avanzaba más rápido. Ahora hay un aparato muy burocrático con gente no tan calificada. Recién últimamente ha entrado gente con más capacidad».

«Últimamente se ha perdido la relación estrecha con los pequeños empresario. Ya no se sienten los protagonistas, no son parte de la toma de decisiones. Aunque están en el directorio sienten que no mandan, que no son escuchados». 